\title{
The Impacts of Visibility and privacy in the workplace on Organizational productivity as conducted through Informal Interactions
}

\author{
Hossein Motamed Chaboki ${ }^{1}$, Ahmad Fauzi A. Wahab ${ }^{2}$, \\ Majid Ansari ${ }^{3}$ \\ ${ }^{1,2}$ (Faculty of Built environment/ University Technology Malaysia, Malaysia) \\ ${ }^{3}$ (Faculty of Management/ University Technology Malaysia, Malaysia)
}

\begin{abstract}
The aim of this paper is to investigate two important factors of workplace layout, visibility and accessibility, and their impacts on "face to face" interaction in the workplace. It is believed that a certain space layout will provide the opportunity for employees to interact with each other thus increases the possibility of team working. The greater level of team working in any organization will lead to higher productivity. The methods to improve the possibility of unplanned communication and ease of interaction within a work area are classified under spatial interconnectedness. This spatial interconnectedness contains workers' visibility, worker 's movements and accessibility within the work space. In this study, employees in an office were asked to complete a survey that calculated variables of the research. They received a questionnaire including measures for each of the key variables. Some of these procedures were taken from a research made for a large corporation, and others were certified measures from the physical workplace contemporary literature. SPSS statistic software was used as software to analyze the data and layout plans was analyzed by Depth map. The results indicate that the visibility of the worker's and the accessibility in a work area is significantly correlated to interaction. The study highlights the importance of workplace productivity and manipulating informal interaction as a measurement of productivity in the office space.
\end{abstract}

Keywords - visibility, accessibility, workplace layout, productivity and "face to face" interaction

\section{INTRODUCTION}

Experts from various fields of knowledge such as sociology, psychology studies, management and organization, architecture and design of the work area and have studied mainly agree on their proposed to create advanced and improved organizational life. This subject takes more credit when researchers in the workplace found that the physical set-up of the social organization of everyday life using their spatial arrangements of space that people move, live and work through them [1]. However if the evolution of the factories and offices as workplaces has a central theme, it is the continued emphasis on the workplace as a resource for efficiency and productivity. The present organizations have become aware of the importance of informal interaction and look at it as a service and notable channel that contribute to individual satisfaction and organizational effectiveness. Unofficial communication considered to relate to multitasking performance [1].

For achieving more productivity, this research is attempting to use interaction as the mediator between layout plan variables and productivity. Visibility and accessibility have been considered in some older literature and selected for analyzing in this survey as layout variables; that those can affect the amount of interactions in the work area.

\section{LITERATURE REVIEW}

Productivity is a master key to the organization's accomplishment; consequently, understanding how gently and rapidly your work line is running is very important. It is explained as the overall output measured against a given number of inputs. Rolloos [2] described the productivity as, "productivity is that which people can produce with the least effort." Increased productivity is considered as a primary goal of business. Modern management all over the world believes that a better working environment relates to more productivity. A profit-oriented organization cannot survive without an acceptable level of productivity; and most if all nonprofit organizations are interested in doing more work without a proportionate increase in money, equipment and employee hours [3].

One of the greatest difficulties that administrators, experience is how to calculate productivity of an organization as a whole. Some companies come up with measuring systems or formulas to calculate it, but acknowledging a dependable metric technique for a corporation can prove to be a bit hard. Brynjolfsson and Hitt [4] summarize the key measure for the productivity with the following humorous passage: 
"Productivity is a simple concept. It is the amount of output produced per unit of input. However, in most of the times, input and output are too difficult to measure and researchers are searching and trying other new methods".

\subsection{COMMUNICATION IN WORKPLACE AND ITS IMPORTANCE IN TEAM WORK}

In recent years, the traditional boundary activities connecting the companies to their environment have been supplemented with a host of informal interactive ventures. Informal interaction has been defined as the social attach of the work area [5], but few experimental researches on what set up such communication have been conducted within organizations. Communication is defined in the Oxford English dictionary (2008) as the "act of importing or exchange of information, letter, message or social dealings; connections or means of access. It is a science and the practice of transmitting information between at least two people." It has been defined also as the transmission and exchange of information, whether spoken or written. Information is conveyed through formal organizational channels of downwards, upwards, and lateral communication. It is also passed along an informal channel-the grapevine. Individuals interact frequently; often develop an identification with each other over time. Communication tends to be much faster in the informal group than formal group communication.

Most "face to face" interaction in the work area is informal, and include conversations and meetings. This type of communication is the basis of most of professional relationships. Researchers defined Informal communications as taking place concurrently in face-to-face settings. They are separated from other methods of office connection like as documents, email, phone, memos, voice mail and FAX. For most workplace employees, informal interaction is a regular workplace performance and for many jobs such as administration it represents the most frequent office activity. Older research indicated that between $25 \%$ and $70 \%$ of time being spent in informal face-to-face interaction.

Informal communication encourages a number of various activities: the performance of work-related tasks; coordination of team work activity; transmission of workplace culture, and social functions such as team building [6]. Its significance is indicated by research into scientific collaboration demonstrating that physical distance is a strong predictor of whether scientists will co-publish, because people who are physically collocated are more likely to communicate frequently and informally.

French and Bell [7] believed groups wield the power in organizations. They stated this belief in several instances. For example they said, "We think teams are the basic building blocks of organizations" (p. 27). And in another passage, they reiterated that thought more strongly. "The basic building blocks of an organization are groups or teams; Therefore, the basic units of change are groups, not individuals" (p. 66). In relation to group performances, interaction is seen as the most import part of working in a team. The ways and the quality of communication between team members, can improve productivity in the workplace.

This paper contributes to the understanding and of informal interaction across organizations and it tries to find a new ways to develop the informal communication by manipulating visibility as an important factor in workplace layout

\section{$1.2 \quad$ FACE TO FACE INTERACTION AND ITS IMPORTANCE}

Face to face is very significant in a work environment where employees have to work on tasks as a team. Study of group work and teamwork provides especially strong support for this indication. Interaction is a process that takes diverse forms on different levels of analysis that is the individual, small group, large group. The physical environment with its diversity and complexity has a great potential to shape the pattern of informal interaction.

In a broad survey of interactions, McKinsey has defined interactions as "the searching, coordinating, and monitoring required exchanging goods and services" [8][9]. Furthermore, as an important measure of productivity in the workplace, collaboration seems to be receiving more attention both industrial practitioners and from researchers. In a 2006 study of C-level executives, IBM [10] found that interaction and partnering are considered very significant for improvement by over 75 percent of the 765 executives contributing in the research

In managing studying, retention and transfer tasks to a group of 70 high school biology undergraduate student. Kirschner, et al. [11] investigated the impacts of group work on their productivity, and discovered that interaction within these groups is necessary for coordination and team accomplishment. Their hypothesis mention that information retention takes less mental effort for individuals learning in the presence of others than those learning alone because the cognitive load is distributed over a number of people. Strubler and York [12] researched teamwork among 500 university academic staff members and discovered that collaboration and communication increased satisfaction and control over the participants' work, and an enhancement in productivity. Finally, Zuckerman [13] found that frequent communication between workers with varying abilities, information and experience improve the group's capacity for creativity and productivity. 


\subsection{EFFECTS OF LAYOUT ON EASE OF FACE-TO-FACE COMMUNICATION}

Considering these expected profits, administrations are interested in improving the chance and frequency of informal FTF communications. Designing a physical layout helpful to frequent FTF interactions One way to do it, and it`s indicated by Penn, et al. [14], the layout of a workplace impacts how workers move and circulate into the workplace. On a primary level, the office layout setting can set up a linked, interactive space or can separate work areas. By supervising a review exploring the frequency of connection with the staffs in spatially isolated workspaces, Penn et al. [14] realized that workers are more likely to interact with their coworkers in spaces that are more accessible. They concluded that the spatial configuration of an office does have a direct impact on the frequency of reported interactions.

Although the density of interactions may not have a direct effect on an individual's productivity, the increase in probability of interacting with other workmen, furthermore raises the chances of teamwork. With team work it can then prompt to better retention of knowledge and in turn, higher productivity[11][12].

\subsection{ENCOURAGING INTERACTION BY USING VISIBILITY AND ACCESSIBILITY}

It is very important to see others and being seen in the workplace. Employees need to show their abilities in performing tasks in the management. Sheridan [15] labels this fact of constant visibility in the workplace and its organization with career accomplishment 'chronic presenteeism'. Visibility is one aspect of spatial interconnection within work space that can predict face-to-face interactions. After making about 25 observations in four different corporations and work spaces, Rashid et al. [16] determined that visibility and location play a role in the frequency of face-to-face, impromptu and informal interactions by measuring visibility through axial map drawings and spatial syntax software program.

Backhouse and Drew [17] videotaped interactions in a workplace and discovered that over $80 \%$ of the communication were informal. Rashid [16] explained the informal interaction in the workplace and set out "When one worker is in motion and the other is at a visible workplace, the deciding item between an unintentional interaction and no interaction is nonverbal cues. Unplanned interactions are discouraged if the employee in motion is focused and looking ahead, or if the employee at the desk is leaning forward and focusing. Similarly, unwitting interactions are encouraged if the employee in motion is looking nearby or if the employee at the desk leaned back and looking around". While the Backhouse and Drew [17] findings weigh on the notion that movement encourages unplanned interactions, Rashid et al. [16] focus on the extent of visibility argues that visibility is a better predictor of face-to-face interactions than movement. However, Penn et al. [14] considered that the lack of visibility also can increases unplanned informal interactions between a seated and a moving person. However, If two workers cannot see each other, then there is no way to know whether or not the other is available for interaction.

Spatial measurement defined by the accessibility of a local "line," or pathway, within an office. Accessibility is a way to control movement through the use of integration of pathways and it encourages people to select to use the same pathways as others out of convenience [18] [14]. By managing a study considering the frequency of connection with the employees in spatially isolated work area, Penn et al. [14] discovered that employees are more likely to interact informally with their coworkers in spaces that are more accessible.

\section{THEORETICAL FRAMEWORK}

Visibility and accessibility are assumed as independent variables that can impact other elements. Informal interactions are considered separately to achieve a better understanding of the model. Based on this model relationship was assumed, and two research questions were made.

Fig 1: conceptual model

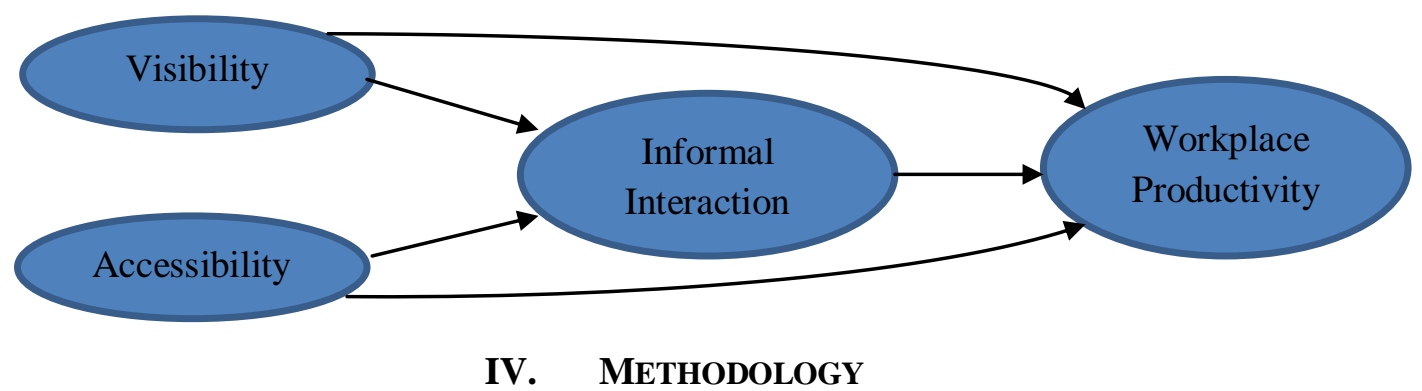

This study tried to determine the causal relationships between two variables of workplace layout, face to face interaction and organizational performance. Descriptive and correlation method is used to analyze the data. 


\section{RESEARCH QUESTIONS}

This study has two research questions as stated below:

Q1: Is the visibility in the office setting correlated to the informal interaction?

Q2: Is the accessibility in the office setting correlated to the informal interaction?

Q3: Is the visibility in the office setting correlated to the productivity?

Q4: Is the accessibility in the office setting correlated to the productivity?

The immediate investigation tried to help the mediation model in which the office layout plan (containing of visibility and accessibility) influences the environment and regularity of the FTF interactions. These interactions should then influence the productivity as seen in Figure 2. The aim of this research was to investigate these thoughts.

Fig 2: interaction aspects

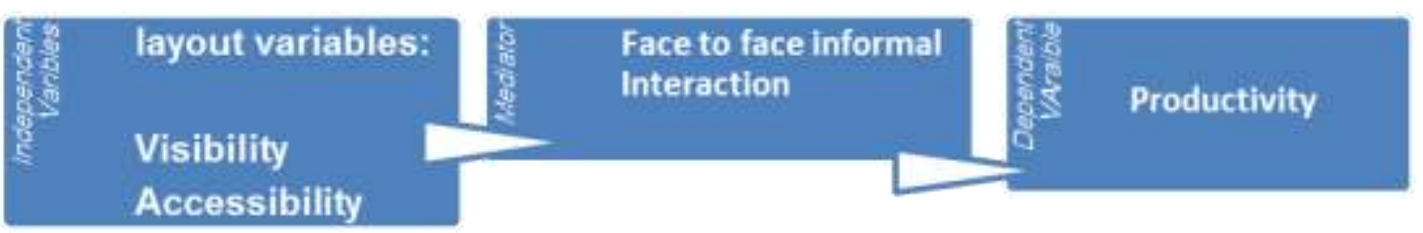

\section{POPUlATION, SAMPLE AND METHOD OF SAMPLING}

In this study, an office with a population of approximately 250 people inhibited in one block of a building was taken as a case study. About 100 questionnaires have been distributed to the population in the selected work places that have various settings. As such the survey will get a better opinion about the impacts of proximity and privacy in various settings.

All the respondents work in all locations and work spaces that have different layout at different floors of the buildings and this will give a valid opinion about the level of visibility and accessibility of the workplace at the organization. This survey managed to get a good representation of the population as a total of $52 \%$ responded to the survey. The percentage of the male employee (55.8\%) responded to the questionnaire is just slightly more than female respondents $(44.2 \%)$. The relatively high number of responses $(52 \%)$ to the questionnaire is expected as the study was conducted under one roof. In this study, visibility is measured by the openness and clarity of the employee's location to observe other employees or facilities and accessibility is measured by the degree of permissiveness of every employee to reach other employees and supervisors, the distance of movement, the level of comfort in this process. Also informal interaction can defined as the frequency of staff meet each other at a certain place without preplanned. Productivity is measured by level of organizational profit, growth and cash flow.

\section{ANALYSIS}

Based on SPSS statistic, questionnaires have been analyzed statistically to find any relationship between variables. Space syntax is being used to find out about the most common space in the workplace for interaction. Depthmap is a one of UCL university products for presenting Space syntax in Architectural and Urban plans and it is a single software platform to achieve a set of spatial network analyses planned to know social routes within the built environment.

\subsection{RELIABILITY}

To evaluate the reliability of the questionnaire, Cronbach's alpha test was used. As Table 1 shows, the reliability coefficient calculated for each Index is greater than 0.7 .

Table (1) Cronbach's alpha

\begin{tabular}{|c|c|c|c|c|c|c|}
\hline Total alpha & Interaction & $\begin{array}{c}\text { Layout } \\
\text { Variable }\end{array}$ & Visibility & Accessibility & Productivity & Variables \\
\hline 25 & 10 & 10 & 5 & 5 & 5 & Number of questions \\
\hline 0.814 & 0.844 & 0.825 & 0.802 & 0.835 & 0.892 & Cronbach's alpha \\
\hline
\end{tabular}


The Impacts of Visibility and privacy in the workplace on Organizational productivity as conducted

1.6 RESULTS:

In table (2), individual and organizational characteristics of the sample survey are presented

Table (2) respondent general information

\begin{tabular}{|c|c|c|c|}
\hline percent & Frequency & Items & Characteristics \\
\cline { 1 - 3 } 55.8 & 29 & Male & \multirow{2}{*}{ Gender } \\
\hline 44.2 & 23 & Female & \multirow{2}{*}{ Years of service } \\
\cline { 1 - 3 } 21.16 & 11 & Under 4 years & \\
\hline 40.38 & 21 & $4-8$ & \\
\hline 26.92 & 14 & 12 and higher & \\
\hline 11.54 & 6 & &
\end{tabular}

The relationships between all variables are shown in table 3. This study used Bivariate Correlations (Pearson Correlation Analysis) to understand the strength of the relationship between two variables, and the significant level set in this research is 0.05 for all relationships.

As it is shown in the table 3 there are acceptable relationships because of their (sig) is more than 0.05 that are not correct Based on SPSS data analysis visibility and interaction have a very strong relationship $(\mathrm{R}=0.784)$ and also there is an acceptable relationship between accessibility and interaction $(\mathrm{R}=0.419)$.

Table (3) Variables, Correlation and Significants

\begin{tabular}{|l|l|l|l|l|l|l|}
\hline \multirow{2}{*}{ Variables } & \multicolumn{2}{|l|}{ Visibility } & \multicolumn{2}{l|}{ Accessibility } & \multicolumn{2}{l|}{$\begin{array}{l}\text { Informal } \\
\text { Interaction }\end{array}$} \\
\cline { 2 - 7 } & $\mathrm{R}$ & Sig & $\mathrm{R}$ & Sig & $\mathrm{R}$ & Sig \\
\hline Accessibility & $0.322^{* * *}$ & 0.027 & ------ & ------ & & \\
\hline $\begin{array}{l}\text { Informal } \\
\text { Interaction }\end{array}$ & $0.584^{* *}$ & 0.000 & $0.419^{* *}$ & 0.026 & ------ & ----- \\
\hline Productivity & $0.521^{* *}$ & 0.001 & $0.415^{* *}$ & 0.006 & $0.517^{* * *}$ & 0.000 \\
\hline
\end{tabular}

In this survey, the relationship between visibility and interaction is found much stronger than the relation between accessibility and interaction. Visibility can be a one important encouraging reason for formal and informal interaction. More visibility can help employees to choose the best possible time to interact with each other. Furthermore it can improve the employees' general knowledge in work area. However interaction needs accessibility in the next level of face to face interaction. Also as shown from the table, all the variables have shown an acceptable correlation with each other except the relationship between visibility and accessibility that they have a relationship $(\mathrm{R}=0.322)$.

Table 4 also shows that the relationship between interaction and productivity is strong $(\mathrm{R}=0.519)$ as stated in the literature.

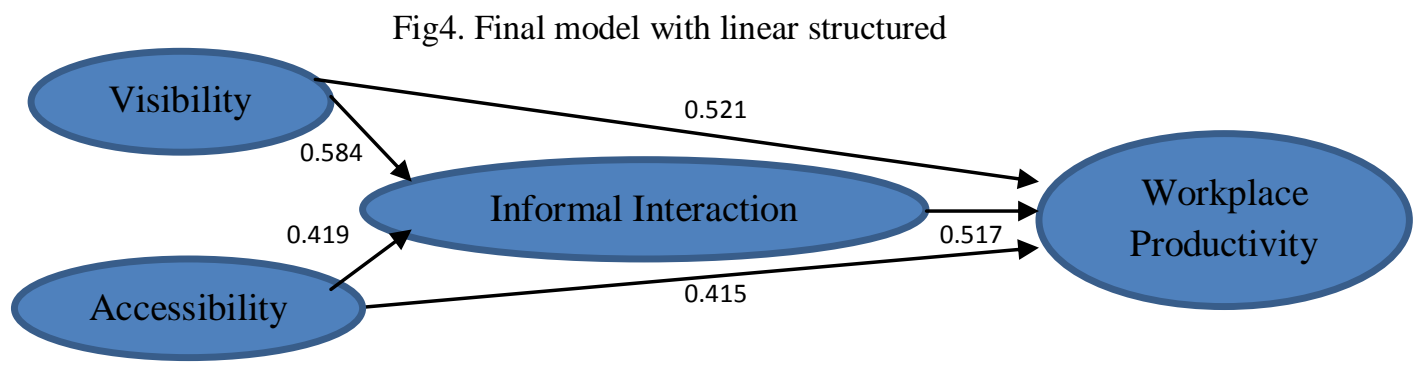

The theoretical framework of this study mixed with amount of correlations between variables in figure 4 for better understanding these relationships.

Hypotheses are analyzed in table 4 and it shows us 2 hypotheses are acceptable in this study and one assumed relationship is not.

As it was expected the impact of visibility on interaction is much more than accessibility, however both correlations between visibility and accessibility are highly positive. It means that more visibility and accessibility in the layout plan lead to more interaction between employees in the office. Also more visibility and accessibility in layout plan can increase organizational productivity. 
Table (4) Hypotheses conditions

\begin{tabular}{|c|c|c|c|c|c|}
\hline Condition & Hypothesis & $\mathrm{R}$ & $\mathrm{Sig}$ & Variable & Variable \\
\hline $\begin{array}{c}\text { Highly } \\
\text { correlated }\end{array}$ & $\mathrm{RQ} 1$ & $0.584^{* *}$ & 0.000 & $\begin{array}{c}\text { Informal } \\
\text { interaction }\end{array}$ & Visibility \\
\hline $\begin{array}{c}\text { Highly } \\
\text { correlated }\end{array}$ & $\mathrm{RQ} 2$ & $0.419^{* *}$ & 0.025 & $\begin{array}{c}\text { Informal } \\
\text { interaction }\end{array}$ & Accessibility \\
\hline $\begin{array}{c}\text { Highly } \\
\text { correlated }\end{array}$ & $\mathrm{RQ} 3$ & $0.521^{* *}$ & 0.001 & Productivity & Visibility \\
\hline $\begin{array}{c}\text { Highly } \\
\text { correlated }\end{array}$ & $\mathrm{RQ} 4$ & $0.415^{* *}$ & 0.006 & Productivity & Accessibility \\
\hline
\end{tabular}

\subsection{SPACE SYNTAX ANALYZES:}

Graph1 and graph 2 are presenting of depthmap result for space syntax analysis. One floor of the workplace has been considered as an example to present the visibility graph of interaction in the work space. Graph1 is visibility graph and more visibility is shown with more whiteness in the layout plan. Openness in the workplace's cells can increase the visibility in the layout and can lead to more interaction and productivity. More visibility can be expected in the corridor and larger rooms. Furniture's common heights are usually under 110 $\mathrm{cm}$ and the height of an employee`s eye is at least $155 \mathrm{~cm}$ from the floor. Thus, they are not considered in the visibility graph.

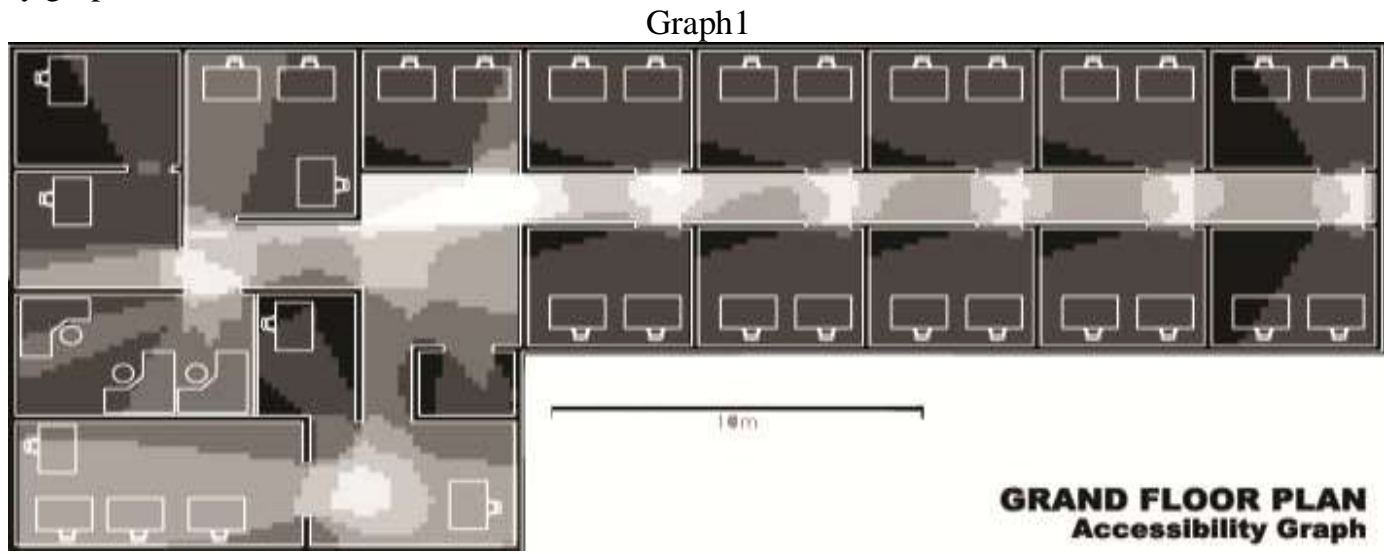

Graph 2 shows the accessibility level in the layout plan, and it has been made by openness, location of employees and furniture. It seems that everything near the corridor or very basic circulation way is more accessible than other places and there is a much more possibilities that interaction start from these places. Furniture setting is so important like walls in the organizational layout whereas an employee wants to stay and move and work. Just by using furniture, designers can manage workflow, movement, organizational hierarchy. Furthermore, Furniture setting can arrange accessibility if we ignore the strong impact of organization culture and rules. In this case lace of inside window and specific organizational rules, caused the visibility graph and the accessibility graph to have a lot of similarity.

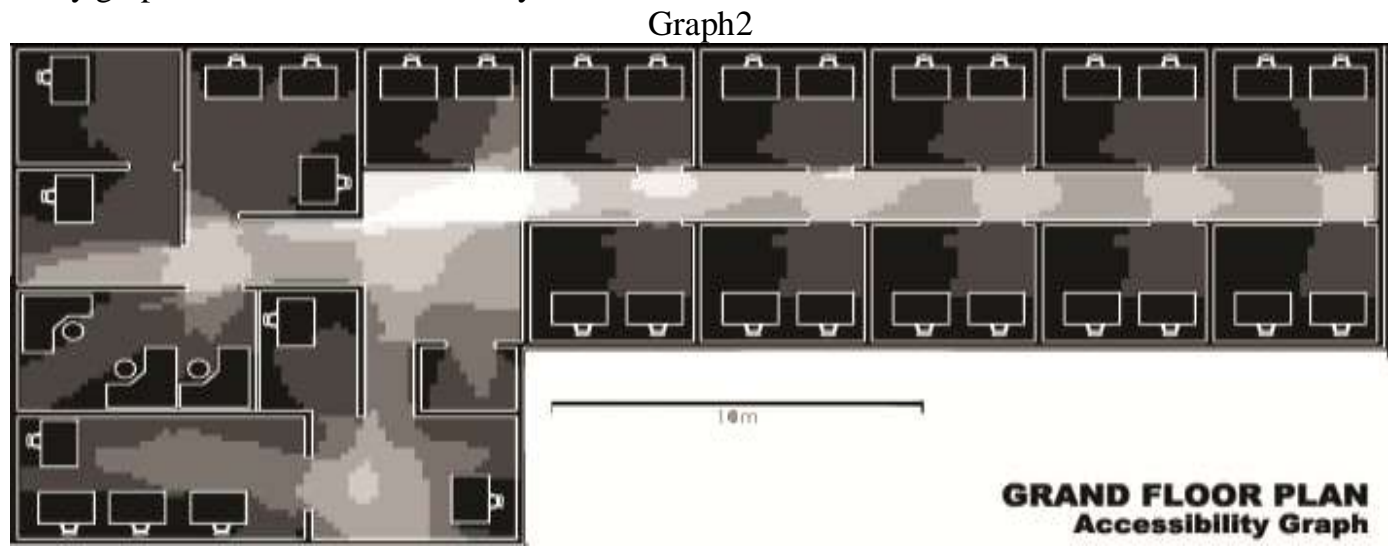




\section{CONCLUSION:}

As we have seen through the results there are significant correlation between physical environment variables, visibility \& accessibility with interaction. As we have discussed through the literature. It is widely assumed that the greater interaction increased the teamwork and organizational productivity. Physical workplace contributes to users' productivity through interaction. Interaction in the workplace at first needs visibility for promoting the chance of interaction in the work area; however after that employees require accessibility also to interact and by making the chance of both formal and informal face to face interaction increase the productivity. Visibility and accessibility also can increase knowledge sharing and team work by improving the quality of interaction. Considering them as two important in design can help designer to control the amount of interaction in the workplace that can lead to more productivity.

Finding also show field of architectural space contribute to organizational study aspect in human resource management. Two disciplines contribute to each other. Human resource management should also consider the role of physical workplace to organizational success. Workplace designers should include understanding of human resource management when designing, not only just provide beautiful workplace. Researchers still not much, explore more this kind of research.

\section{SUGGESTION:}

Visibility and accessibility are not only variables that can affect the workplace layout plan. Privacy, proximity, spatial connectivity, openness of workplace layout and density of employees must consider together in the work spaces to achieving high quality of interaction. For further research other layout variables that can affect interaction and productivity should also be taken into consideration.

\section{Journal Papers:}

\section{REFERENCES:}

[1] Sundstrom, E., De Meuse, K. P., Futrell, D. (1990) Work teams: applications and effectiveness, American Psychologist, February, $120-133$

[2] Rolloos, M. (1997) Een gezond binnenmilieu betaalt zichzelf terug Praktijkboek Gezonde Gebouwen.October, A2001-3 18. As cited in Chandrasekar, 2011

[3] Becker, F. D., et al. "Office Design in a Community College: Effect on Work and Communication Patterns." Environment and Behavior. Nov., 1983.

[4] Brynjolfsson, E. and L. Hitt (1998). "Information Technology, Workplace Organization and the Demand for Skilled Labor: Firm Level Evidence.” Mimeo. MIT, Stanford and Wharton.

[5] Holmes, Janet, and Meredith Marra (2004). Relational Practice in the workplace: Women "s talk or gendered discourse Language In Society 33. 377-398

[6] Kraut, R.E., Dumais, S. \& Koch, S. (1989). Computerization, productivity and quality of work-life. Communications of the ACM, 32, 220-238

[7] French, W. L., \& Bell, C. H. (1999). "Organization development: Behavioral science interventions for organization improvement." Upper Saddle River, NJ: PrenticeHall.

[8] Butler, p. (1997). "A revolution in interaction” The McKINSEY Quarterly 1997 Number 1

[9] Johnson, Bradford C. (2005). "The next revolution in interactions". The McKINSEY Quarterly Nov. 2005

[10] IBM: Expanding the Innovation Horizon. The Global CEO Study 2006, IBM Global Business Services. IBM, 2006

[11] Kirschner, F., Paas, F., \& Kirschner, P. A. (2009). Individual and group-based learning from complex cognitive tasks: Effects on retention and transfer efficiency. Computers in Human Behavior, 25(2), 306-314.

[12] Strubler, D. C., \& York, K. M. (2007). "An exploratory study of the Team Characteristics Model using organizational teams". Small Group Research, 38(6), 670-695.

[13] Zuckerman, E. W. (2001). Networks, Diversity, and Productivity: The Social Capital of Corporate R\&D Teams. Organization Science, 12(4), 502-517.

[14] Penn, A., Desyllas, J. \& Vaughan, L. (1999). The space of innovation: interaction and communication in the work environment. Environment and Planning B-Planning \& Design 26(2), 193-218

[15] Sheridan, A. (2004), 'Chronic Presenteeism: The Multiple Dimensions to Men's Absence from Part-Time Work,' Gender, Work and Organization, 11, 2, 207-225

[16] Rashid, M., Kampschroer, K., Wineman, J., \& Zimring, C. (2006). Spatial layout and face-to-face interaction in office study of the mechanisms of spatial effects on face-to-face interaction. Environment and Planning B: Planning and Design, 33, 825-844

[17] Backhouse A. \& Drew P. (1992). The design implications of social interaction in a workplace setting. Environment and Planning B: Planning and Design, (19), 573-584.

\section{Books:}

[18] Hillier, B. 1984, The social logic of space, Cambridge university press 